\title{
Reduced fouling ultrafiltration membranes via in-situ polymerisation using polydopamine functionalised titanium oxide
}

Muayad al-Shaelia , Hanaa M. Hegab ${ }^{\mathrm{a}}$, Xiya Fang ${ }^{\mathrm{b}}$, Lizhong He ${ }^{\mathrm{a}}$, Chang Liu ${ }^{\mathrm{a}}$, Huanting Wanga Kaisong Zhang and Bradley P. Ladewig ${ }^{a, d, c}$

${ }^{a}$ Monash University, Department of Chemical Engineering, Clayton, VIC, 3800, Australia

${ }^{\mathrm{b}}$ Centre for Electron Microscopy, Monash University, Clayton, VIC, 3800, Australia

c Institute of Urban Environment, Chinese Academy of Sciences, No. 1799, Jimei Road, Xiamen 361021, China

${ }^{`}$ Barrer Centre, Department of Chemical Engineering, Imperial College London, Exhibition Road, London SW7 2AZ, United Kingdom

- Institute for Micro Process Engineering (IMVT), Karlsruhe Institute of Technology, Hermann-von-Helmholtz-Platz 1, 76344 Eggenstein-Leopoldshafen, Germany

Keywords: Ultrafiltration membranes, Polydopamine, Titanium dioxide, Anti-fouling property, Anti-bacterial

\section{Abstract}

The trade-off phenomenon between selectivity and permeation flux is a major challenge in pressure-driven membranes, and specifically for ultrafiltration membranes. Currently, many research studies have been performed to try to increase permeability while maintaining the rejection at a high level. However, in most of these studies, the improvement of permeability was accompanied by a decrease in rejection or vice versa. To tackle this problem, $\mathrm{TiO}_{2}$ nanoparticles were attached on the surface of PES membranes using polydopamine as adhesive agent. In general, it is quite challenging to attach/bind $\mathrm{TiO}_{2}$ on the surface of membranes due to agglomeration of nanoparticles. Therefore, we developed a practical, simple and a scalable method to attach $\mathrm{TiO}_{2}$ nanoparticles (NPs) on the top surface of membrane using one-step dip 
coating. Experimental results revealed that the modified layer enhanced the hydrophilicity of the PES UF membranes as confirmed by the decrease of contact angle from. As a result, the modified membranes exhibited a significant improvement in anti-fouling properties, with 12 times higher water permeation flux (962 LMH for pDA-f-TiO $2-\mathrm{PES30}$ ) as compared to the pristine PES membranes (79.9 LMH). The static adsorption of BSA on the surface of membranes was reduced from $\left(60 \mu \mathrm{g} / \mathrm{cm}^{2}\right.$ for pristine PES to $21 \mu \mathrm{g} / \mathrm{cm}^{2}$ for $\mathrm{pDA}-\mathrm{f}-\mathrm{TiO}_{2}$ PES120).

Furthermore, the modified PES membranes displayed a higher flux recovery ratio $(97 \%)$ and fouling reversibility (98.62\%) than pristine PES membrane (37.63\%). Also, the coated PES membranes bestowed a good antibacterial property relative to the pristine one. Besides, the membranes showed better physical and chemical stability as compared with unmodified PES membranes. Thus, this study provided a facile approach for enhancing the anti-fouling performance of PES ultrafiltration membranes.

\section{Introduction}

The scarcity of water resources is one of the most important issues worldwide. Currently, rapid urbanization and industrialization, population growth, and climate disruption exacerbate the problem of water scarcity. The worldwide demand for fresh, clean and abundant water has increased significantly over that from the past. Therefore, sustainable technologies are required urgently to solve this global challenge [1]. Among the adapted strategies, membrane based separation technologies has been extensively developed to extend and renew water resources by producing a high-quality water due to their exceptional properties such as low operating cost, high separation efficiency, reliability and simplicity than conventional water treatment technologies[2,3]. As part of membrane separation technology, ultrafiltration (UF) membranes with higher membrane flux, higher anti-fouling property and stability are urgently required as UF membranes are extensively used for wastewater remediation [4-6], industrial wastewater treatment [7], reverse osmosis (RO) pre-treatment and other food separation applications, chemical and biochemical industries [8-10].

In comparison to other commercialised polymer materials, polyethersulfone (PES) is a thermosetting polymer used for fabrication ultrafiltration applications due to its excellent chemical properties, high thermal stability and mechanical strength, and film-forming properties [11-17]. However, the strongly hydrophobic character of PES results in membranes which are easily fouled by adsorption of pollutants during separation and purification processes, which ultimately results in decreasing water permeation flux and degraded 
separation properties [11].. Numerous methods to modify PES membranes have been proposed involving physical blending, surface coating, surface grafting and surface modification. Among these modification methods, the incorporation of hydrophilic and antimicrobial nanoparticles into membranes has received significant interest due to facile processing and predictable separation performance. These nanoparticles include silver nanoparticles (Ag), gold $(\mathrm{Au})$, carbon nanotubes (CNTs), graphene oxide $(\mathrm{GO})$, zinc oxide $(\mathrm{ZnO})$, zeolite and titanium dioxide $\left(\mathrm{TiO}_{2}\right)$ [18-21]. Among the mentioned nanoparticles, titanium dioxide $\left(\mathrm{TiO}_{2}\right)$ has been identified as an effective antifouling nanomaterial for organic foulants in wastewater treatment processes due to its outstanding properties such as high hydrophilicity, antibacterial properties, stability, non-toxicity, photocatalytic activity and low cost [22]. However, the uniform dispersion and firmly attaching/binding of $\mathrm{TiO}_{2} \mathrm{NPs}$ on the membrane surface are a crucial factor for constructing membranes with stable, long-lasting high performance. Tightly bonding $\mathrm{TiO}_{2}$ NPs on the surface of membranes can result in a high surface hydrophilicity and reduced resistance to water permeation, whilst uniformly dispersed $\mathrm{TiO}_{2} \mathrm{NPs}$ can help decrease the likelihood of blocking membrane pores. A common shortcoming in existing studies relates to the agglomeration of $\mathrm{TiO}_{2} \mathrm{NPs}$, resulting in less enhancement in membrane performance and anti-fouling properties. In many cases, the NPs are totally enclosed by the polymer matrix, rendering them barely useful in modifying the surface hydrophilicity. Thus, covalent crosslinking and self-assembly approaches are usually adopted in thin film hybrid membranes to try and address the above-mentioned problems. However, these approaches rarely modify the surface of PES membrane effectively due to the weak binding force between PES membranes and $\mathrm{TiO}_{2}$ NPs. Therefore, it is required to find a scalable method to attach $\mathrm{TiO}_{2} \mathrm{NPs}$ on the top surface of membrane surface.

Dopamine (DA) is currently applied as a promising agent for membrane surface modification owing to its outstanding properties including self-polymerization on any substrate, higher anchoring capability and the possibility for further functionalization [23-26].

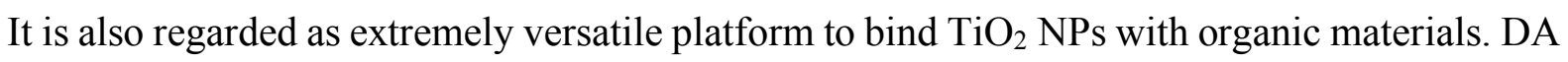
undergoes the oxidative self-polymerization process in an alkaline environment to generate a surface-adhering polydopamine (pDA) film for different organic and inorganic materials [24]. $\mathrm{pDA}$ remains reactive due to the existence of amine and hydroxyl functional groups, which makes it suitable for further functionalization and modification for various applications [27]. A variety of membranes including reverse osmosis (RO), nanofiltration (NF), and ultrafiltration (UF) membranes have been modified with pDA coating through hydrogen bonding, $\pi-\pi$ stacking, the action of van der Waals forces and chelation [28]. This allows the 
grafting of different polymeric functional groups with their antifouling moieties such as zwitterionic polymers, hyper-branched polyglycerol and nanomaterials [29-34]. Kasemset et al.[35] have studied the effect of deposition pDA on the performance of polyamide (PA) reverse osmosis membranes for applications of oil/water. The results showed that membrane flux decreased with increasing dopamine solution concentration and polydopamine deposition time. Jiang et al[36]. have discovered the fundamental surface characteristics of pDA-coated PVDF membranes. The pDA could stick robustly on the surface of PVDF membrane and effectively decrease the water contact angle.. Ou et al.[37] have deposited successfully a uniform $\mathrm{TiO}_{2}$ films on different polymer substrates (PE and PTFE) pre-modified by pDA coating and investigated the biocompatibility of modified materials.

To the best of our knowledge, rare studies focus on one-step binding of $\mathrm{TiO}_{2}$ nanoparticles on PES membrane surface via dopamine. In this study, a simple, practical and facile coating technique of PES UF membrane was proposed using a single-step in situ-dipcoating oxidation polymerization concept of DA to robustly immobilize/bind $\mathrm{TiO}_{2} \mathrm{NPs}$ onto the membrane surface. Different coating times were applied including (15, 30, 60 and 120) min. The modified and pristine PES membranes were characterised using various surface characterization techniques. Moreover, the membrane performance of the modified membranes was assessed in terms of permeation flux, rejection, antifouling, anti-adhesion and antibacterial.

\section{Materials and Methods}

\subsection{Materials}

Commercial PES membranes were purchased from Sterlitech Corporation (USA). $\mathrm{TiO}_{2}$ NPs (Powder, anatase type, 99.8\% metals basis, $25 \mathbf{~ n m ~ s i z e ) ~ a n d ~ D A ~ h y d r o c h l o r i d e ~ w e r e ~}$ obtained from Sigma Aldrich, Australia. Bovine serum albumin (BSA) was used as foulant models during UF experiments and were purchased from (Sigma Aldrich, Australia). $\mathrm{NaOH}$ (purity $\geq 99$, Merck KGaA Company, Germany). Deionized water and ultrapure water were used in the experiments.

\subsection{Modification of PES UF membranes}

PES membranes were immersed in ultrapure water overnight prior to the experiment. $\mathrm{TiO}_{2}(0.05 \mathrm{wt} \%)$ was dissolved in solution of Tris-HCl buffer $(15 \mathrm{mM}, \mathrm{pH} 8.5)$ and the obtained solution was fully dispersed using ultrasonication. Subsequently, DA ( $2 \mathrm{wt} \%)$ was added to the $100 \mathrm{~mL}$ of the prepared solution to obtain the $\mathrm{DA}^{-\mathrm{TiO}_{2}}$ hybrid. PES membranes were immediately dip-coated into $\mathrm{DA}-\mathrm{TiO}_{2}$ solution and mixed by shaking (see scheme 2). The 
reaction proceeded at room temperature (RT) for different intervals; 15, 30, 60 and $120 \mathrm{~min}$, denoted as pDA-f-TiO 2 -PES15, pDA-f-TiO 2 -PES30, pDA-f-TiO $2-\mathrm{PES} 60_{2}$ and pDA-f-TiO 2 PES120, respectively. Afterwards, the coated PES membrane was rinsed with deionized water at least four times and placed in the oven for 10 minutes. All the modified PES membranes were kept in deionized water (DI) for $24 \mathrm{hr}$ before use.

\subsection{Membrane characterization}

\subsubsection{Membrane Surface Characterization}

The surface chemical structure of modified and pristine PES membranes was characterized by X-ray photoelectron spectroscopy using an AXIS Nova spectrometer (Kratos Analytical Inc., Manchester, UK) with a monochromated Al Ka source at a power of $180 \mathrm{~W}$ $(15 \mathrm{kV} \times 12 \mathrm{~mA})$ and a hemispherical analyser operating in the fixed analyser transmission mode. Moreover, the chemical compositions of membranes were collected using Fourier transform infrared spectra (FTIR, PerkinElmer, USA). Additionally, the surface morphology and mapping of membrane was examined by scanning electron microscopy-electron dispersive energy (SEM-EDS, FEI Magellan 400 FEG SEM, Hillsboro, USA). Finally, the hydrophilicity of membrane surface was determined using a contact angle measurement (CA) (OCA15EC, Dataphysics, Germany). Results were collected from the average of at least ten values at different areas for each membrane sample.

\subsubsection{Permeation test}

The water flux of the pristine PES and hybrid PES membranes was determined using a HP4750 dead-end ultrafiltration cell (Sterlitech Corporation, USA) as shown in Figure S1. Circular pieces of membrane samples with $25 \mathrm{~mm}$ diameter and $14.6 \mathrm{~cm}^{2}$ effective membrane area were cut from the coated membranes and were stored in double deionized water (DDI) for $60 \mathrm{~min}$ before use. Then the filtration cell was filled with DDI (to volume $300 \mathrm{ml}$ ) and then attached to $5 \mathrm{~L}$ water reservoir. During the filtration test, the membranes are first compacted at pressure $0.15 \mathrm{MPa}$ for $60 \mathrm{~min}$ to get a steady filtration. Once the steady state was achieved, the water flux $\left(\mathrm{J}_{\mathrm{w} 1}\right)$ was measured at $0.1 \mathrm{MPa}$ pressure by measuring the permeate weight with the time using an electronic balance connected with a computer. The data from the electronic balance was connected to a computer using LabVIEW software. Three membrane samples were tested to calculate the averages of water flux values.

\subsubsection{Fouling measurements}

Dynamic fouling mode was utilized to study the anti-fouling performance of the coated PES membranes [38]. The pristine and modified PES membranes are first compacted with deionized water at $0.15 \mathrm{MPa}$ to get a stabilise flux. After 60 min filtration, the water flux was 
measured at pressure at $0.1 \mathrm{MPa}$. Afterwards; BSA protein solution (1000 ppm) was tested as foulant to accelerate the fouling onset for an hour and pressurized to $0.1 \mathrm{MPa}$. The flux $\left(\mathrm{J}_{\mathrm{BSA}}\right)$ was recorded at the last 10 minutes of the run. The concentrations of BSA in the permeate and feed sides were spectroscopically determined at $280 \mathrm{~nm}$ using Varian Cary 100 Bio UV-VIS spectrophotometer. The rejection ratio $(\% \mathrm{R})$ of the membrane was calculated by the following equation [39]:

$R(\%)=\left(1-\frac{C_{p}}{C_{f}}\right) * 100$

Where $\mathrm{R}(\%)$ represented the rejection coefficient of the membrane, $\mathrm{C}_{\mathrm{f}}$ and $\mathrm{C}_{\mathrm{p}}(\mathrm{mg} / \mathrm{mL})$ are the concentrations of feed solution and permeate stream, respectively. The concentration of sodium alginate in the solution was calculated based on the calibration curve prepared in advance.

Then, the fouled membranes were underwent in cleaning process. In physical cleaning, the fouled membranes were rinsed with deionized water for $30 \mathrm{~min}$ and the flux was measured from the labview software at $100 \mathrm{MPa}$. In chemical cleaning, the fouled membrane was rinsed with solution of $\mathrm{NaOH}(2 \mathrm{~g} / \mathrm{l})$ for 20 minutes, following by rinsing with deionized water three times to remove the $\mathrm{NaOH}$ solution, then the flux was measured from the labview software at $100 \mathrm{Mpa}$. For each cleaning step (physical and chemical), the flux was measured $\left(\mathrm{J}_{\mathrm{w} 2}\right)$ at 100 Mpa. Three sequential fouling cycles were applied for each membrane.

To determine membrane performance, flux recovery ratio (\% FRR) was calculated using the following equation $[40,41]$ :

$\operatorname{FRR}(\%)=\frac{J_{w 2}}{J_{w 1}} \times 100$

Where the $\left(\mathrm{J}_{\mathrm{w} 2}\right)$ and $\left(\mathrm{J}_{\mathrm{w} 1}\right)$ are the flux after cleaning process and before fouling process.

To study the membrane fouling in detail, total fouling resistance $\left(\mathrm{R}_{\mathrm{t}}\right)$, reversible fouling resistance $\left(R_{r}\right)$ and irreversible fouling resistance $\left(R_{i r}\right)$ were determined using the following equations respectively[42].

$R_{t}=\frac{J_{W 1}-J_{p}}{J_{W 1}} \times 100$

$R_{r}=\frac{J_{W 2}-J_{p}}{J_{W 1}} \times 100$

$R_{i r}=\frac{J_{W 1}-J_{\mathrm{W} 2}}{J_{W 1}} \times 100$

Where $J_{p}$ : is the flux of BSA foulant model. $R_{t}$ is the sum of $R_{r}$ and $R_{i r}$. 


\subsubsection{Static protein adsorption}

The adsorption capacity of the membrane surface was determined using protein adsorption experiments. BSA was used as model foulant. Circular pieces of membranes with diameter of $25 \mathrm{~mm}$ were cut from the coated membranes and washed with double deionized water several times before use. Then, the circular pieces of membranes were placed in filtration cell by exposing the filtration surface of membrane to BSA solution $(500 \mathrm{ppm})$. The filtration cell was then incubated in a shaker with $150 \mathrm{rpm}$ speed at $25^{\circ} \mathrm{C}$ for $24 \mathrm{hrs}$. The concentration changes of BSA were measured and the adsorption capacity was calculated based on the concentration changes of BSA using equation $6[38,43]$ :

$Q=\frac{\left(C_{a}-C_{b}\right) V}{A}$

Where $\mathrm{Q}\left(\mu \mathrm{g} / \mathrm{cm}^{2}\right)=$ adsorbed protein, $\mathrm{C}_{\mathrm{a}}(\mathrm{g} / \mathrm{L})=$ initial concentration of BSA, $\mathrm{C}_{\mathrm{b}}(\mathrm{g} / \mathrm{L})=$ final concentration of BSA, A $\left(\mathrm{cm}^{2}\right)=$ area of membrane sample, and $\mathrm{V}(\mathrm{L})=$ volume of the BSA solution

The concentration of BSA macromolecules was measured using an ultraviolet-visible spectroscopy (mini-1240, Shimadzu, Japan) at absorbance $280 \mathrm{~nm}$. The obtained results were the average of the protein adsorption on four samples of membrane. After static protein fouling, the flux of the fouled membrane was recorded, and the flux was recorded again after cleaning cycle. The flux recovery ratio after static protein was calculated by recording the flux before and after fouling tests.

\subsubsection{Antibacterial test}

The antibacterial properties of the membrane were analyzed by the plate counting method[44]. Briefly, $(1.8 \times 2.5) \mathrm{cm}$ rectangular membrane samples were prepared and sterilized with $80 \%$ ethanol prior to the test. The sterilized membranes samples were immersed into broth LB medium cultured with Escherichia. coli BL21 (OD600 = 0.1) and incubated at $37^{\circ} \mathrm{C}$ and $250 \mathrm{rpm}$ shaking (Thermoline Scientific Equipment Pty Ltd., Sydney, Australia) for $24 \mathrm{hr}$. The membrane samples were collected after 12 hours incubation and washed with 7.5 $\mathrm{mL}$ phosphate-buffered saline (PBS, $\mathrm{pH}$ 7.4) buffer for $20 \mathrm{~min}$ to remove unattached cells. The washed membranes were then transferred into $7.5 \mathrm{~mL}$ fresh PBS buffer and sonicated (Power Sonic 405, Thermoline Scientific Equipment Pty Ltd., Sydney, Australia) for another 20 minutes to extract attached cells. The optical densities of the extraction solutions were recorded with a spectrometer (DR 5000 TM UV-Vis Spectrophotometer, Hach, Australia). The extraction solutions were diluted with filter-sterilized PBS to normalized OD600 of 0.0001 and spread on LB agar plates. The plates were incubated overnight at $37^{\circ} \mathrm{C}$ and the number of colonies were counted. 


\subsubsection{Stability evaluation}

To evaluate the coating stability, two modes of stability have been done: the first mode is physical stability and the second one is chemical stability. In regard to physical stability, the unmodified and modified PES membranes were immersed into DDI water bottle. Then, the samples with the water bottle were placed in into a water path under a continuous shaking at a speed of 100 rpm at $30{ }^{\circ} \mathrm{C}$ for 15 days.

The chemical stability was done by immersing the pristine and modified PES membranes in different membrane washing agent $(\mathrm{NaOCl}$ solution concentration $=500 \mathrm{ppm}, \mathrm{pH}=9.5$, sodium hydroxide solution $\mathrm{NaOH}$ at $\mathrm{pH}=13$ and hydrochloric acid solution $\mathrm{HCl}$ at $\mathrm{pH}=2$ ) respectively. Each chemical stability test lasted for 15 days. The membranes after physical and chemical washing were characterised by CA and membrane performance and the results are tabulated.

\section{Results and discussion}

3.1. Mechanism of in-situ polymerization process

The procedure for in-situ polymerization of $\mathrm{pDA}-\mathrm{f}-\mathrm{TiO}_{2}$ onto the PES membrane surface is depicted in Scheme S1. As shown in Scheme $\mathrm{S} 1$, the $\mathrm{TiO}_{2} \mathrm{NPs}$ were immobilized/coated well on the surface of PES membrane using polydopamine as an adhesive agent. The reaction has occurred at room temperature $\left(25^{\circ} \mathrm{C}\right)$. The coating time was varied from $15 \mathrm{~min}$ to $120 \mathrm{~min}$.

Scheme 2 shows the mechanism to link pDA and $\mathrm{TiO}_{2}$ NPs without using any crosslinkers or using any chemical agent. the oxidation of catechol in dopamine to O-quinone (dopamine quinone) by alkaline $\mathrm{pH}$-induced oxidation $(\mathrm{pH}=8.5)$. Its intramolecular cyclization, oxidation to dopaminechrome, formation of 5,6-dihydroxyindole (DHI) and further oxidation to 5,6-indolequinone (IDQ). It is notable that the mixture of dopamine, quinone and indole may co-exist in solution after the first steps since the oxidation and cyclization may be complete. The mixtures of these units undergo various pathways to form the PDA, which is later connect with metal oxide $\left(\mathrm{TiO}_{2}\right)$ NPs. 


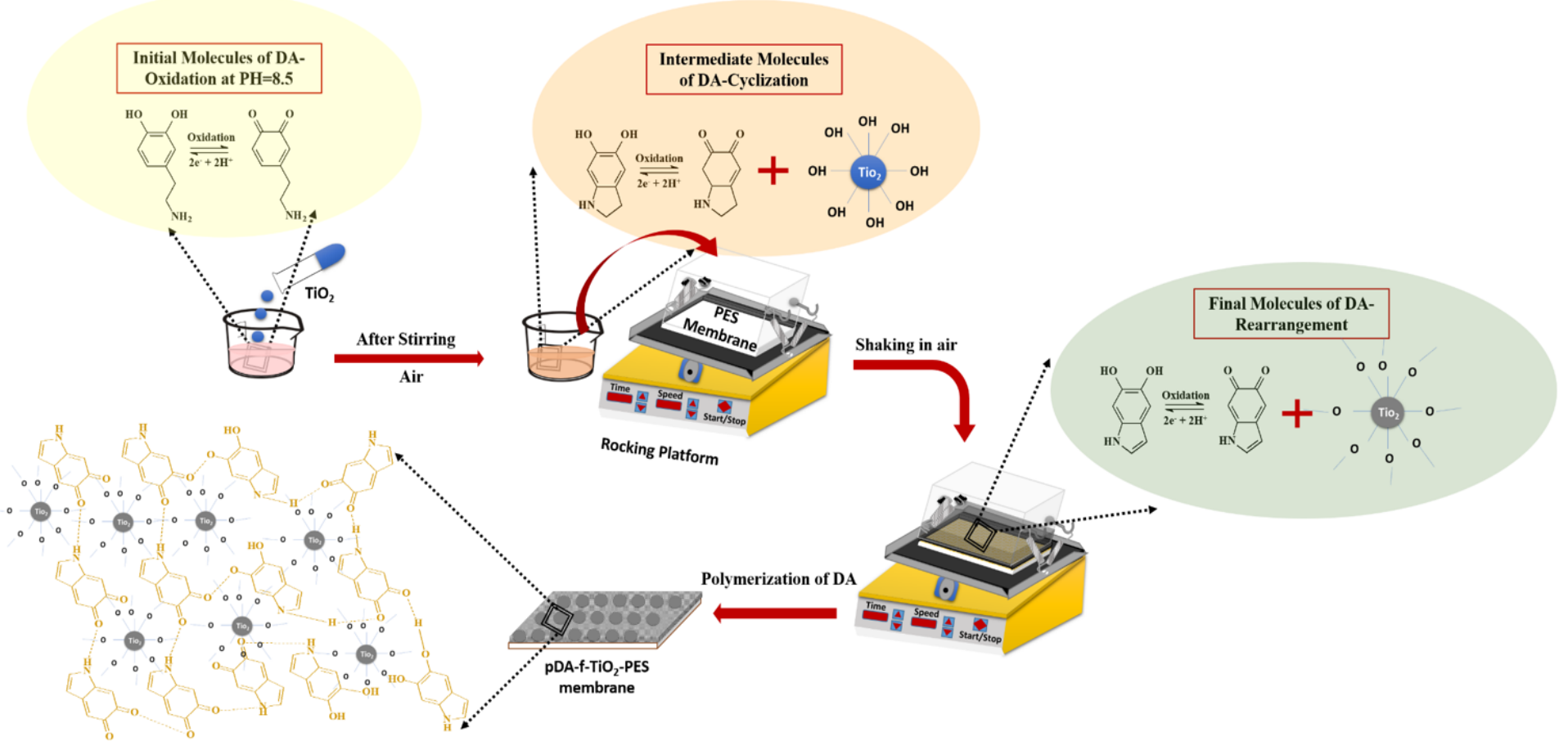

Scheme 2. The mechanism of linking of polydopamine (pDA) and titanium oxide nanoparticles $\mathrm{TiO}_{2}$ NPs on the surface of PES UF membranes. Three steps were observed in the scheme as presented in different colors.

\subsection{Membrane morphology}

Fig. 1 shows the membrane photographs and SEM top surface morphologies of membranes before and after the coating of $\mathrm{pDA}-\mathrm{f}-\mathrm{TiO}_{2}$ layer on the surface of PES UF membrane. As observed in Fig. 1 the first top row, during the process of oxidative selfpolymerization of DA-f-TiO 2 , the color of the modified PES membrane surface was changed from white clear (transparent) to light grey after 15 and 30 min coating time and then change further to dark grey colour after long coating time 60 and $120 \mathrm{~min}$. The reason could be attributed to the effect of different dip-coating time (15 min, $30 \mathrm{~min}, 60 \mathrm{~min}$, and $120 \mathrm{~min}$ ), indicating that the layer of $\mathrm{pDA}-\mathrm{f}-\mathrm{TiO}_{2}$ was successfully coated/grafted on the surface of PES membranes.

It also observed from Fig. 1, the second middle row that the pore size of PES membrane was getting smaller over the modification time because of a thin layer of pDA-f- $\mathrm{TiO}_{2}$ covers the top surface of the membrane (as confirmed by SEM images and EDX in Fig. 2). The white 
circle in the third row of Fig. 2 indicates the presence of $\mathrm{TiO}_{2}$ nanoparticles within the PES membrane surface. It is postulated that longer coating time resulted in increasing the amount of pDA $\mathrm{f}-\mathrm{TiO}_{2}$ on the surface of the membrane. The stability and formation of $\mathrm{pDA}-\mathrm{f}-\mathrm{TiO}_{2}$ layer on PES membranes may be assigned to the non-covalent interactions including hydrogenbonding interaction, $\pi-\pi$ interaction and electro-static interaction.

To verify the presence of $\mathrm{TiO}_{2}$ NPs on the surface of PES membranes, SEM images, EDX scan images and EDX mapping were taken for pristine PES and modified PES membranes and the results are shown in Fig. 2. As is seen in first row Fig. 2, pristine PES membrane shows no trace of $\mathrm{TiO}_{2}$ NPs. However, the modified PES membranes showed that the $\mathrm{TiO}_{2}$ NPs is anchored on the surface after modification. These images indicate the successful coating of $\mathrm{pDA}-\mathrm{f}-\mathrm{TiO}_{2}$ layer on the surface of PES membranes This result is in agreement with the reported literature[45].

The coating of $\mathrm{pDA}-\mathrm{f}-\mathrm{TiO}_{2}$ layer onto PES membranes surfaces was further verified by EDX-Ti-mapping analysis and the results are also shown in Fig. 2 (Middle row and third row). The Ti peak was not detected in the EDX spectrum of the pristine PES membrane; however, the Ti peak was detected for the modified PES membranes at $0.45 \mathrm{keV}$ as shown in Figure 3.3b-d Middle row. The coated PES membranes also showed the main peaks at $0.27 \mathrm{keV}$ and $0.52 \mathrm{keV}$, which corresponded to $\mathbf{C}$ and $\mathbf{O}$ peaks. The EDX results confirmed the successful coating of pDA-f- $\mathrm{TiO}_{2}$ layer on the top of PES membranes.

The EDX image could determine the elements that present in the membranes and usually be used to analyse the distribution of a chosen element. The results of EDX mapping are shown in the third raw Fig. 2 . The EDS Ti Maps of the modified membranes in Fig. 2 clearly show where the Ti rich particles are located. The areas with a high concentration of $\mathrm{Ti}$ in the EDX map well match the locations of particles in the SEM image. Furthermore, the green dots in the Ti EDX map of the pristine membrane represented only the noise from the spectrum background. The SEM images, EDX scan images, and EDX mapping indicate that the whole

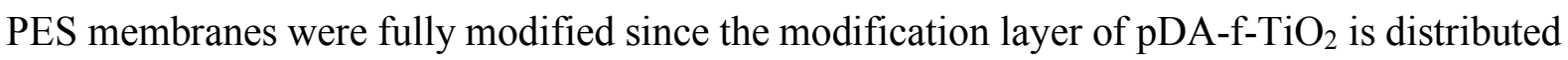
uniformly on the inner pores of membranes. 
Pristine PES
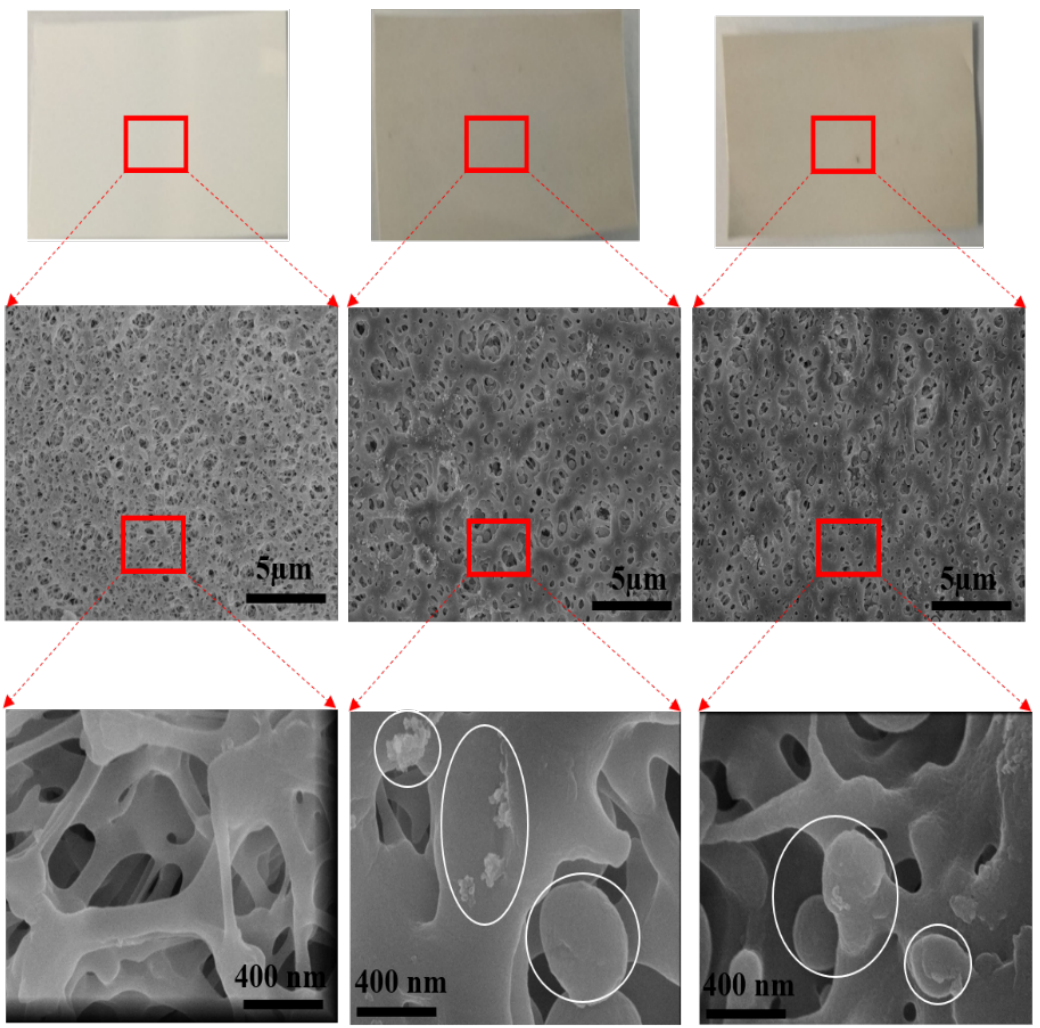

pDA60-f-TiO ${ }_{2}$-PES pDA120-f-TiO 2 -PES
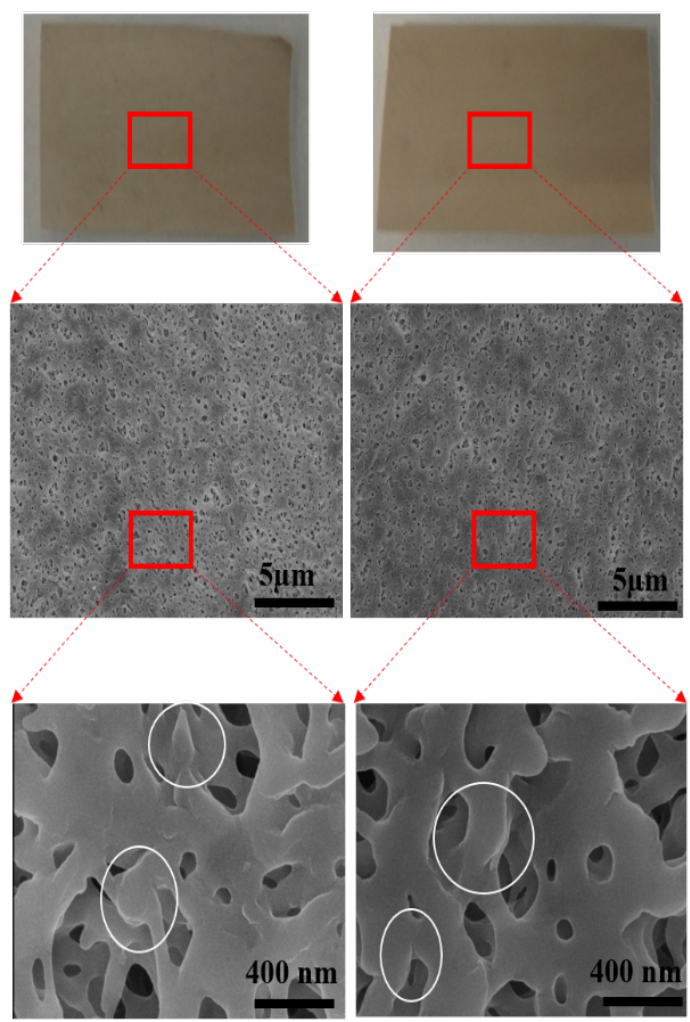

Fig. 1. Photographs and SEM morphology images of top surface PES UF membranes after coating with layer of pDA-f- $\mathrm{TiO}_{2}$. The first top row was represented the photos of membrane before and after coating with $\mathrm{pDA}-\mathrm{f}-\mathrm{TiO}_{2}$. The middle and bottom rows was represented the SEM top surface morphologies of membranes before and after coating with pDA-f-TiO ${ }_{2}$ All the SEM images were taken using Magellan. 

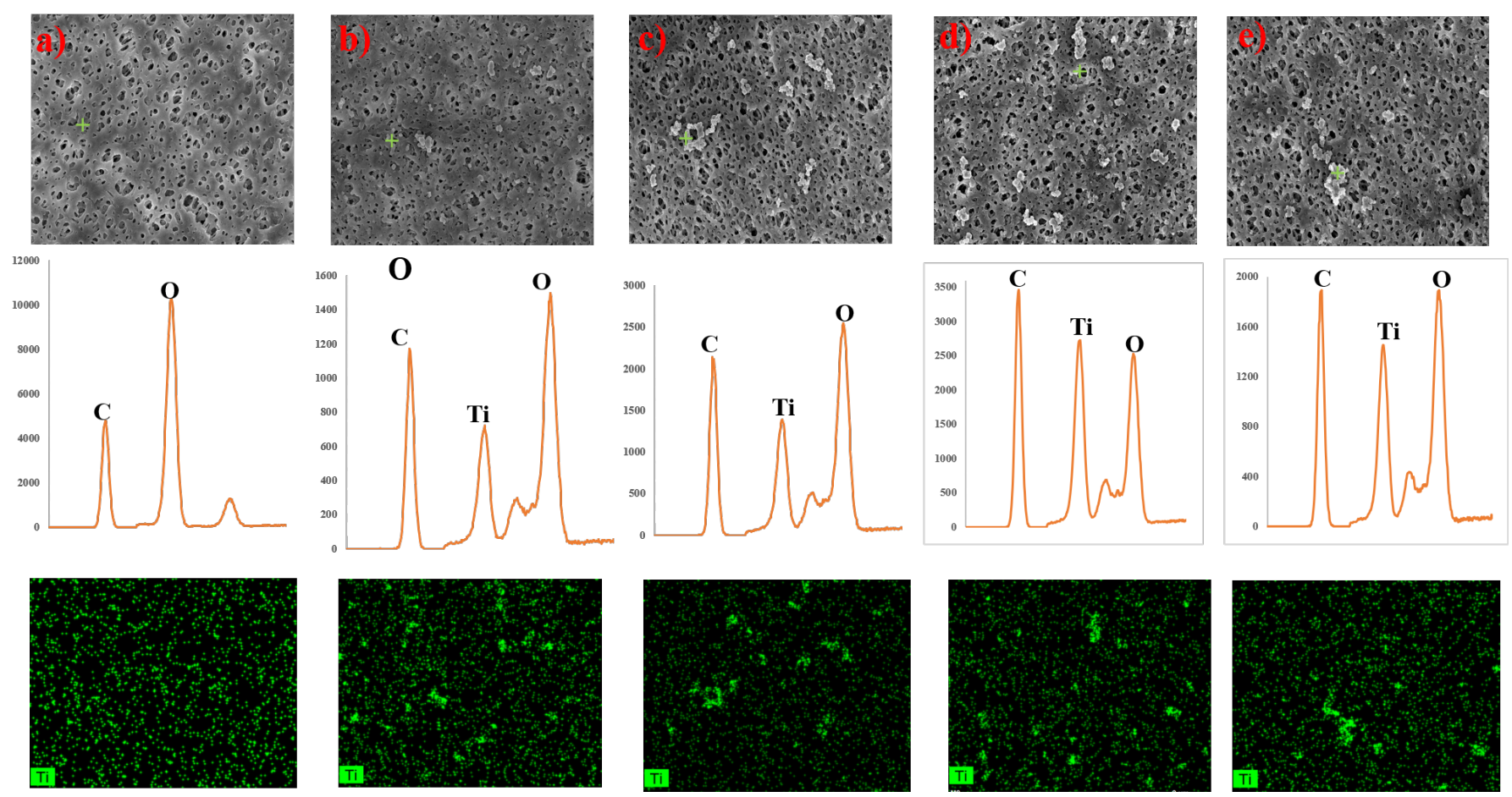

Fig. 2. Energy dispersive X-ray analysis (EDX) and EDX Ti Maps of a) pristine PES b) pDAf-TiO - PES15 c) pDA-f-TiO - PES30 d) pDA-f-TiO - PES60 e) pDA-f-TiO - PES120 UF membranes. The first top raw represents the SEM top surface morphology of pristine and modified PES membranes. The middle raw represents the EDX spectrum of pristine and modified PES membranes to confirm the presence of $\mathrm{TiO}_{2}$ on PES surface. The last raw represents the EDX Ti maps.

\subsection{Chemical compositions of membrane surface}

To check the chemical structure of pristine PES and modified PES membranes, FTIR and XPS were undertaken and the results are presented. The FTIR spectrums of the unmodified and modified PES membranes are presented in Fig. 3. The absorption bands for each membrane, which correspond to the PES structure, are observed at $1244 \mathrm{~cm}^{-1}$ (aromatic ring stretching vibrations), $1488 \mathrm{~cm}^{-1}$ (C-C bond stretching), and $1580 \mathrm{~cm}^{-1}$ (benzene ring

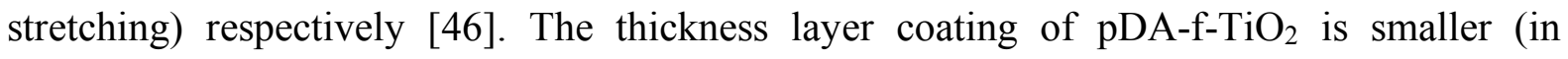
nanometer) than the detecting-depth of FTIR measurement $(10-14 \mu \mathrm{m})$, so the functional groups of pDA and $\mathrm{TiO}_{2}$ layer did not have high intensity in FTIR spectrum. This result in line with the previously reported in the literature. 


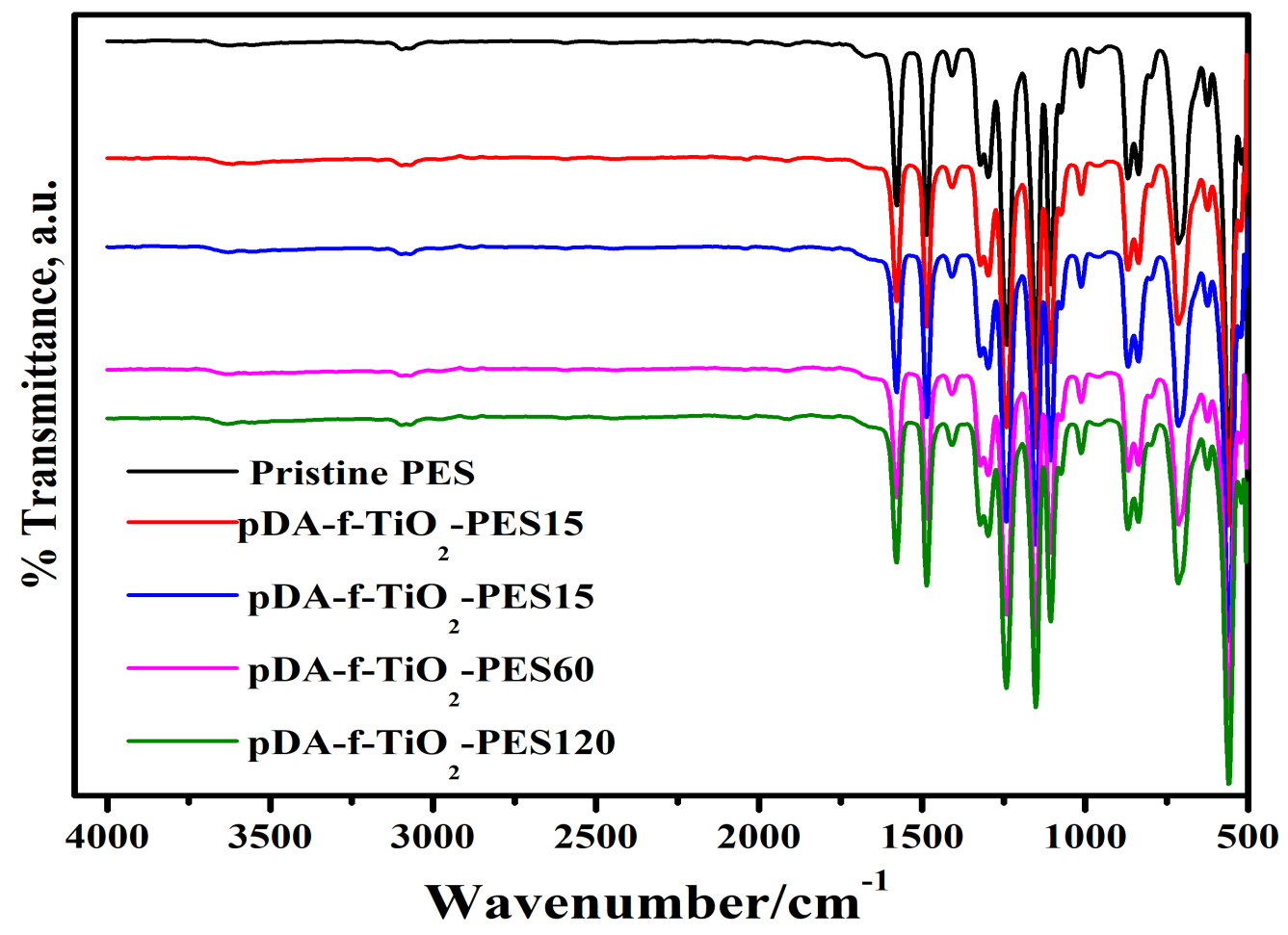

Fig. 3. FTIR spectra for pristine and modified PES UF membranes.

The XPS analysis was conducted to check the elemental chemical composition of pristine and modified PES membranes and the results are shown in Table.1 and Fig. 4, As presented in Table 1 and Fig. 4, the pristine PES membrane shows the presence of C1S (81.04), followed by the elements of O1s (13.95) and S2p (3.23). There are no N1s and Ti2p observed in pristine PES membranes. However, the PES/pDA-f- $-\mathrm{TiO}_{2}$ displays the peaks of $\mathrm{O} 1 \mathrm{~S}$ and $\mathrm{N} 1 \mathrm{~S}$ and Ti2p, which implies the readily coating of pDA-f-TiO 2 layer on the surface of PES membranes. The content of nitrogen (N1s) element was increased after modification from (2.21 to 4.50), indicating that the modified membranes were indeed covered with pDA. Whilst, the content of titanium (Ti2p) were decreased from (0.44 to 0.2$)$, indicating that the membranes are fully covered with pDA layer after 120 min coating. All the evidences confirmed the successful grafting of PES membranes with pDA-f-TiO ${ }_{2}$ layer. The O-CO group was found to be the most abundant in the modified PES membranes, indicating the presence of $\mathrm{pDA}$ and $\mathrm{TiO}_{2}$. 
Table 3.1. XPS data of pristine and modified PES UF membranes.

\begin{tabular}{llcccc}
\hline Sample & PES & $\begin{array}{c}\text { pDA-f- } \\
\text { TiO }^{-}- \\
\text {PES15 }\end{array}$ & $\begin{array}{c}\text { pDA-f- } \\
\text { TiO-PES30 }\end{array}$ & pDA-f-TiO $_{2}$-PES60 & $\begin{array}{c}\text { pDA-f-TiO } \\
\text { PES120 }\end{array}$ \\
\hline \%Atomic & Mean & Mean & Mean & Mean & Mean \\
O 1S & $13.95 \pm 0.17$ & $15.78 \pm 0.38$ & $15.04 \pm 0.21$ & $15.24 \pm 1.16$ & $15.12 \pm 0.48$ \\
N 1S & 0 & $2.21 \pm 0.08$ & $2.83 \pm 0.21$ & $3.41 \pm 0.05$ & $4.50 \pm 0.29$ \\
C 1S & $81.04 \pm 0.54$ & $78.85 \pm 0.44$ & $79.51 \pm 0.18$ & $79.05 \pm 1.41$ & $78.75 \pm 0.72$ \\
S 2p & $3.23 \pm 0.10$ & $2.52 \pm 0.11$ & $2.39 \pm 0.08$ & $2.21 \pm 0.19$ & $1.56 \pm 0.03$ \\
Si 2p & $0.18 \pm 0.06$ & $0.18 \pm 0.02$ & $0.11 \pm 0.03$ & $0.09 \pm 0.10$ & $0.06 \pm 0.07$ \\
Ti 2p & $0.00 \pm 0.00$ & $\mathbf{0 . 4 4} \pm 0.12$ & $\mathbf{0 . 1 2} \pm 0.01$ & $\mathbf{0 . 1 6} \pm 0.01$ & $\mathbf{0 . 2 0} \pm 0.02$ \\
\hline
\end{tabular}

\begin{tabular}{|c|c|c|c|c|c|c|}
\hline \multirow[t]{2}{*}{$\begin{array}{l}\text { Relative } \\
\text { fraction } \\
\text { of C, \% }\end{array}$} & PES & $\begin{array}{l}\text { pDA-f- } \\
\mathrm{TiO}_{2}- \\
\text { PES15 }\end{array}$ & $\begin{array}{l}\text { pDA-f- } \\
\mathrm{TiO}_{2}- \\
\text { PES30 }\end{array}$ & $\begin{array}{l}\text { pDA-f- } \\
\mathrm{TiO}_{2}- \\
\text { PES60 }\end{array}$ & $\begin{array}{l}\text { pDA-f- } \\
\text { TiO }^{-} \\
\text {PES120 }\end{array}$ & Assignments \\
\hline & Mean & Mean & Mean & Mean & Mean & \\
\hline $\mathrm{C} 1$ & $62.21 \pm 0.94$ & $60.77 \pm 0.79$ & $58.74 \pm 0.94$ & $59.80 \pm 2.29$ & $53.53 \pm 0.90$ & $\mathrm{C}-\mathrm{C}, \mathrm{C}-\mathrm{H}$ \\
\hline $\mathrm{C} 2$ & $20.59 \pm 1.08$ & $21.09 \pm 0.80$ & $21.32 \pm 1.17$ & $17.93 \pm 1.56$ & $19.62 \pm 1.30$ & C-C, C-H, C-S \\
\hline $\mathrm{C} 3$ & $14.08 \pm 0.60$ & $15.34 \pm 0.33$ & $16.47 \pm 0.24$ & $17.67 \pm 0.72$ & $21.43 \pm 0.83$ & $\mathrm{C}-\mathrm{N}, \mathrm{C}-\mathrm{O}$ \\
\hline $\mathrm{C} 5$ & $1.37 \pm 0.28$ & $1.49 \pm 0.08$ & $2.09 \pm 0.22$ & $3.07 \pm 0.06$ & $4.27 \pm 0.27$ & $\mathrm{C}=\mathrm{O}, \mathrm{N}-\mathrm{C}=\mathrm{O}$ \\
\hline C6 & $0.06 \pm 0.06$ & $0.19 \pm 0.05$ & $0.27 \pm 0.04$ & $0.37 \pm 0.14$ & $0.52 \pm 0.14$ & $\mathrm{O}-\mathrm{C}=\mathrm{O}$ \\
\hline $\mathrm{C} 7+\mathrm{C} 8$ & $1.69 \pm 0.11$ & $1.11 \pm 0.14$ & $1.12 \pm 0.07$ & $1.18 \pm 0.15$ & $0.61 \pm 0.19$ & Shake-up \\
\hline
\end{tabular}




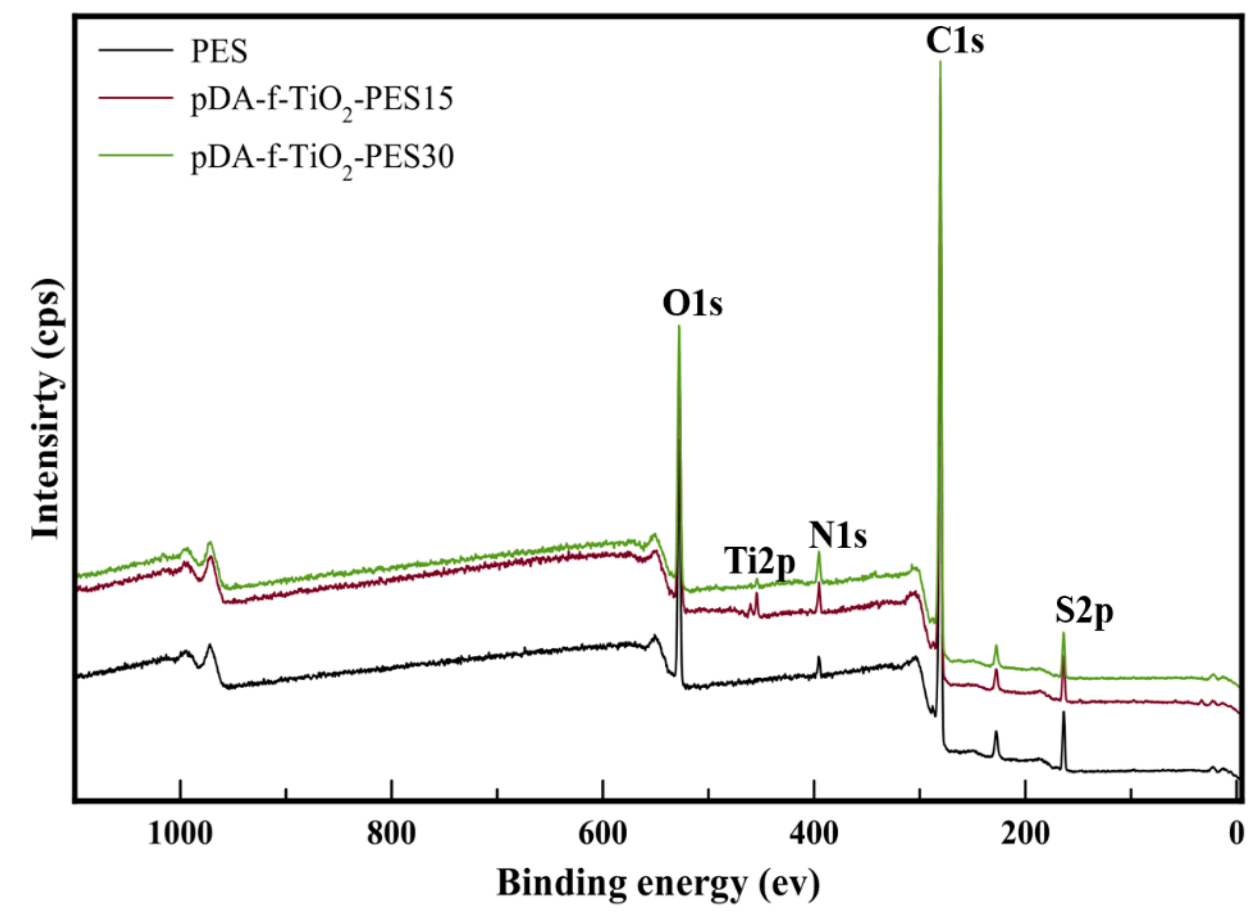

Fig. 4. X-ray photoelectron spectroscopy (XPS) wide spectra of pristine and pDA-f-TiO ${ }_{2}$ modified PES UF membranes at 15 and 30 coating times.

3.4. Membrane hydrophilicity, permeating properties, and static adsorption of membranes

The membrane hydrophilicity is a vital aspect to improve the antifouling performance of membrane [47]. The hydrophilicity of pristine and modified PES UF membranes was determined using contact angle (CA) measurement as illustrated in Fig. 5. The results revealed that the contact angle for unmodified PES membranes was $61^{\circ}$ due to the intrinsic hydrophobic characteristic of the PES membrane. After coating the membrane with layer of $\mathrm{pDA}-\mathrm{f}-\mathrm{TiO}_{2}$, the modified PES membranes exhibited significant decrement in CA $\left(25.9^{\circ}, 24.8^{\circ}, 20.6^{\circ}\right.$ and $13.1^{\circ}$ after $15 \mathrm{~min}, 30 \mathrm{~min}, 60 \mathrm{~min}$ and $120 \mathrm{~min}$ dip-coating) respectively. The significant reduction in the results of contact angle was due to an increase in surface hydrophilicity of PES membrane due to presence of hydrophilic polydopamine and $\mathrm{TiO}_{2} \mathrm{NPs}$. Longer coating times resulted in more pDA-f-TiO 2 layer deposited on the surface of PES membranes, which is consequently leading to increasing the hydrophilicity of membranes. The combination of polydopamine and $\mathrm{TiO}_{2}$ can provide a good membrane performance. These results are similar to the data reported in other literature[36, 37, 48-50] 


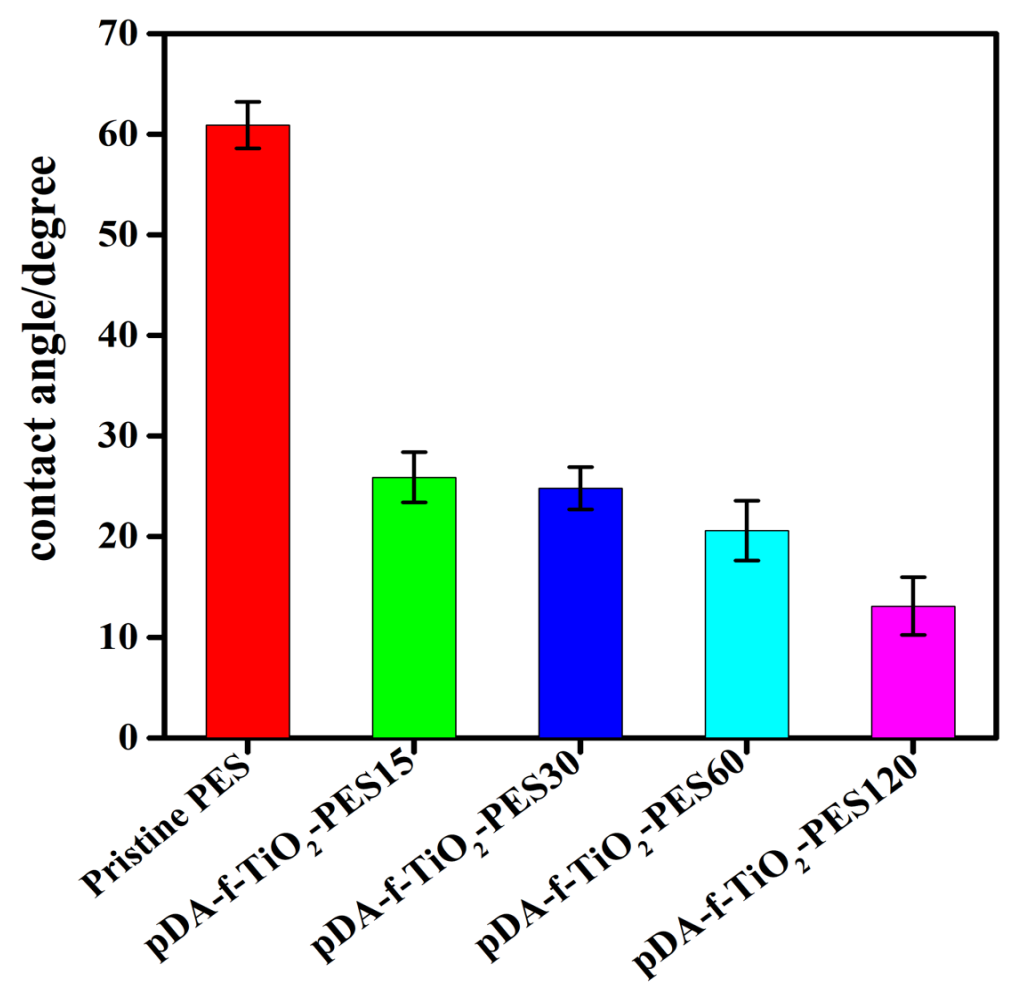

Fig. 5. Contact angle measurements of pristine and modified PES UF membranes. The bar height is the average of five contact angle measurements for each membrane and the error bars represent $+/$ - one standard deviation.

The results of water flux $\left(\mathrm{J}_{\mathrm{w} 1}\right)$ and rejection of BSA for pristine and hybrid PES UF membranes are illustrated in Fig. 6. It can be seen that the water flux $\left(\mathrm{J}_{\mathrm{w} 1}\right)$ for unmodified PES membrane was 79.9 LMH due to the hydrophobic nature of the PES polymer. After coating the PES with hydrophilic layer of pDA-f- $\mathrm{TiO}_{2}$, the water flux was increased remarkably from 79.9 $\mathrm{LMH}$ for pristine PES to $962 \mathrm{LMH}$ for $\mathrm{pDA}-\mathrm{f}-\mathrm{TiO}_{2}-\mathrm{PES} 30$, which is $91 \%$ higher than that of pristine PES, indicating that the membrane become more hydrophilic as confirmed by the results of contact angle (Fig. 6). A further increase in coating the membranes with $\mathrm{pDA}-\mathrm{f}-\mathrm{TiO}_{2}$ layer for 60 and $120 \mathrm{~min}$, the water flux was reduced to 584.6 LMH for pDA-f-TiO $2-\mathrm{PES} 60$ and 478.4 LMH for pDA-f-TiO2-PES120, which is still higher than pristine PES membranes. Longer coating time resulted in more $\mathrm{pDA}-\mathrm{f}-\mathrm{TiO}_{2}$ layer deposited on the surface of PES membranes (complete coverage of $\mathrm{pDA}-\mathrm{f}-\mathrm{TiO}_{2}$ on the membrane surface), which is consequently decrease the membrane pore size and increase the transport resistance. This results is in agreement with the previously reported by [51].

Fig. 6 also shows the results of \% BSA rejection. BSA was used as a macromolecule organic foulants in this study. It can be observed that the modified PES membranes showed a higher \% 
retention rate of $\mathrm{BSA}(\% \mathrm{R})$ than unmodified PES membranes due to reduce membrane pore size as a results of increasing coating time of $\mathrm{pDA}-\mathrm{f}-\mathrm{TiO}_{2}$ layer.

Interestingly, there is an optimized $\mathrm{pDA}-\mathrm{f}-\mathrm{TiO}_{2}$ modification time (degree) for obtaining the best membrane performance with regard to pure water flux. During pDA-f- $\mathrm{TiO}_{2}$ modification, the pure water flux initially increases until reaching the maximum at $962 \mathrm{LMH}$ and then decreases significantly with increasing coating time. On the other hand, BSA rejection continuously increases with the coating time. Therefore, at the initial stage (the hydrolysis time $\leq 30 \mathrm{~min}$ ) of $\mathrm{pDA}-\mathrm{f}-\mathrm{TiO}_{2}$ modification, both water flux and BSA rejection have simultaneously been improved which is similar to the recent report by[52] using the atom layer deposition method to modify PVDF membranes. The water flux increases with the coating time due to the increased surface hydrophilicity and reduced water permeation resistance at the initial pDA-f- $\mathrm{TiO}_{2}$ modification stage. However, with further increase in the coating time ( $\left.\geq 60 \mathrm{~min}\right)$, too many layers of $\mathrm{pDA}-\mathrm{f}-\mathrm{TiO}_{2}$ are tightly bound on the surface of membranes, which may result in the thicker pDA-f- $\mathrm{TiO}_{2}$ layer and increase the water permeation resistance. Thus, the water flux decreases. Based on the results above, 30 min coating time is considered a suitable time for the optimal membrane properties.

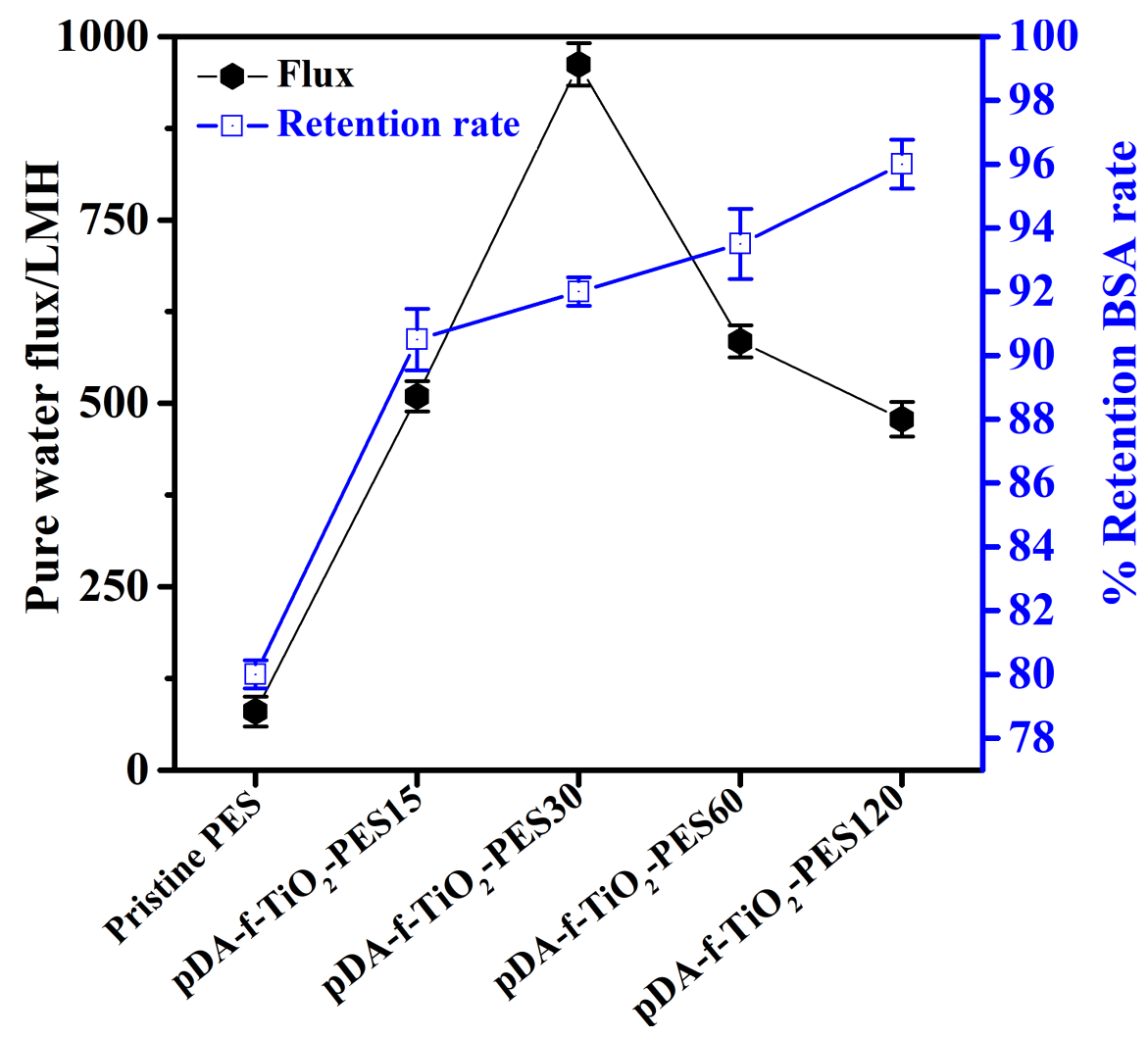

Fig. 6. Pure water flux and \% BSA Rejection rate of pristine PES and modified PES UF membranes. The flux reached a maximum point at $962 \mathrm{LMH}$ for 30 minutes coating then 
reduced significantly to 584.6 $\mathrm{LMH}$ and $478.4 \mathrm{LMH}$ for 60 and 120 minutes coating respectively. The $+/-$ represents the standard deviations of five measurements of flux and rejection were taken for each membrane sample.

The flux recovery ratio (\% FRR) is an indicative factor in evaluating the antifouling performance of membrane, in which higher \% FRR reflects improved antifouling performance. Fig.7 shows the results of flux recovery ratio of unmodified and modified PES membranes. After three cycles of physical and chemical cleaning, the \% FRR for all modified PES UF membranes was higher (97.1\% after 120 min of coating) than unmodified PES membranes $(42.1 \%)$ as the coated membrane surfaces were highly hydrophilic as confirmed by the results of contact angle (Fig.5.) The higher hydrophilicity of membranes could cause the formation of water molecules layer. This is in line with the results of contact angle. It is well-known that improving surface hydrophilicity and pure water flux positively affect the antifouling performance.

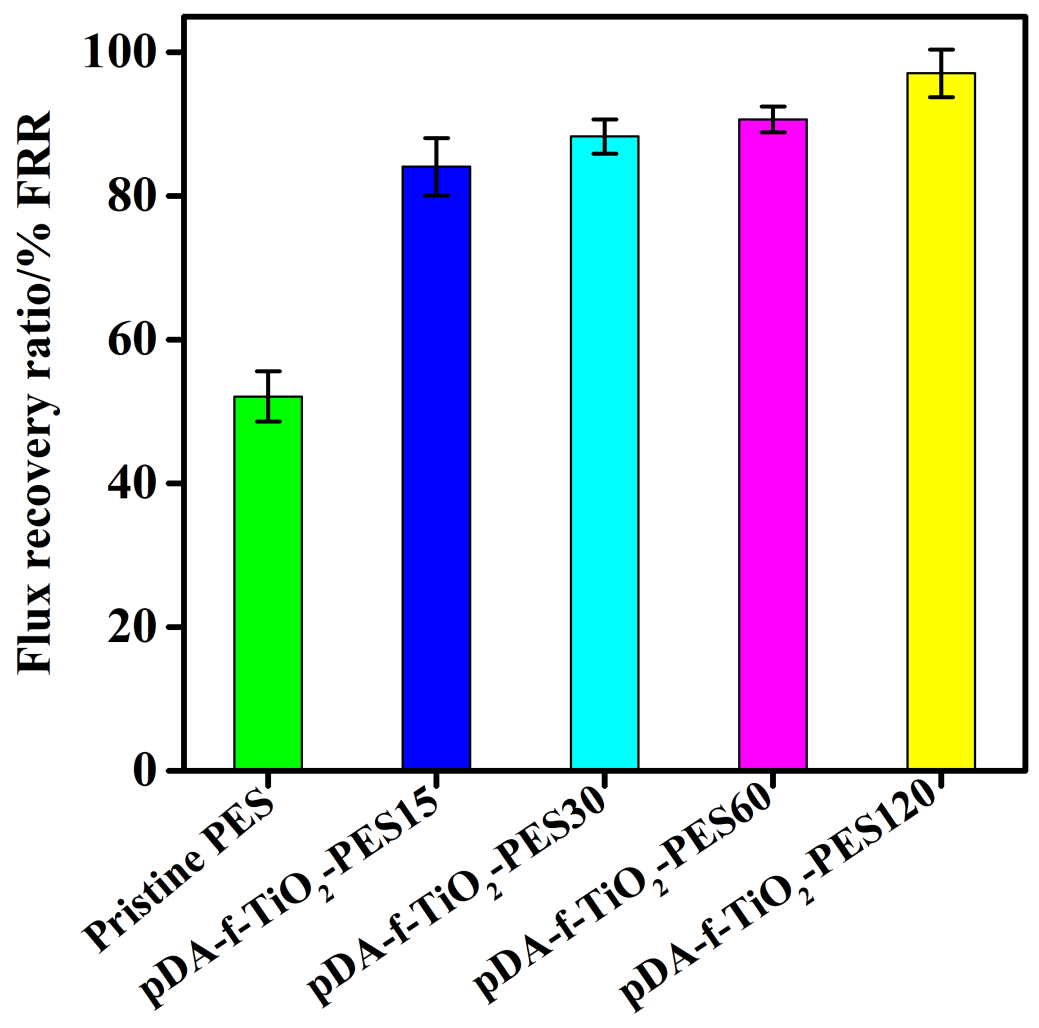

Fig. 7. \% Flux recovery ratio (\% FRR) of PES and modified PES UF membranes. The bar height is the average of five $\%$ FRR measurements, and the error bars represent $+/$ - one standard deviation. 
The amount of adsorbed BSA macromolecules was evaluated in static protein (BSA) adsorption test and the result is shown schematically in Fig. 8. It was clearly observed the adsorption amount of BSA is related to the hydrophilicity of membrane and to the morphology. PES membrane has higher BSA adsorbed amount due to the hydrophobic nature of PES polymer. In hydrophobic surfaces, the affinity between the membrane surface and protein is weakened, which allow the protein to easily adhere on the membrane surface and dominate the boundary layer. However, the modified PES membranes have less amount of BSA adsorbed $\left(21 \mu \mathrm{g} / \mathrm{cm}^{2}\right.$ after $120 \mathrm{~min}$ of coating) than pristine PES $\left(60 \mu \mathrm{g} / \mathrm{cm}^{2}\right)$. The significant decrement in BSA adsorption amount indicates that the modified PES membranes are more hydrophilic. Hydrophilic surfaces can create a tightly bounded water layer, which represents as physical barrier to inhibit the adhesion of BSA molecules on membrane surfaces [53-56].

The flux recovery ratio (\% FRR) was calculated again after BSA adsorption and the results are shown in Fig. 8. It can be noted that the modified PES membranes showed higher $\%$ FRR than pristine PES membrane counterpart. The results of \% FRR after protein adhesion was roughly similar to the $\%$ FRR after cleaning cycles, indicating that the PES membranes are hydrophilic.

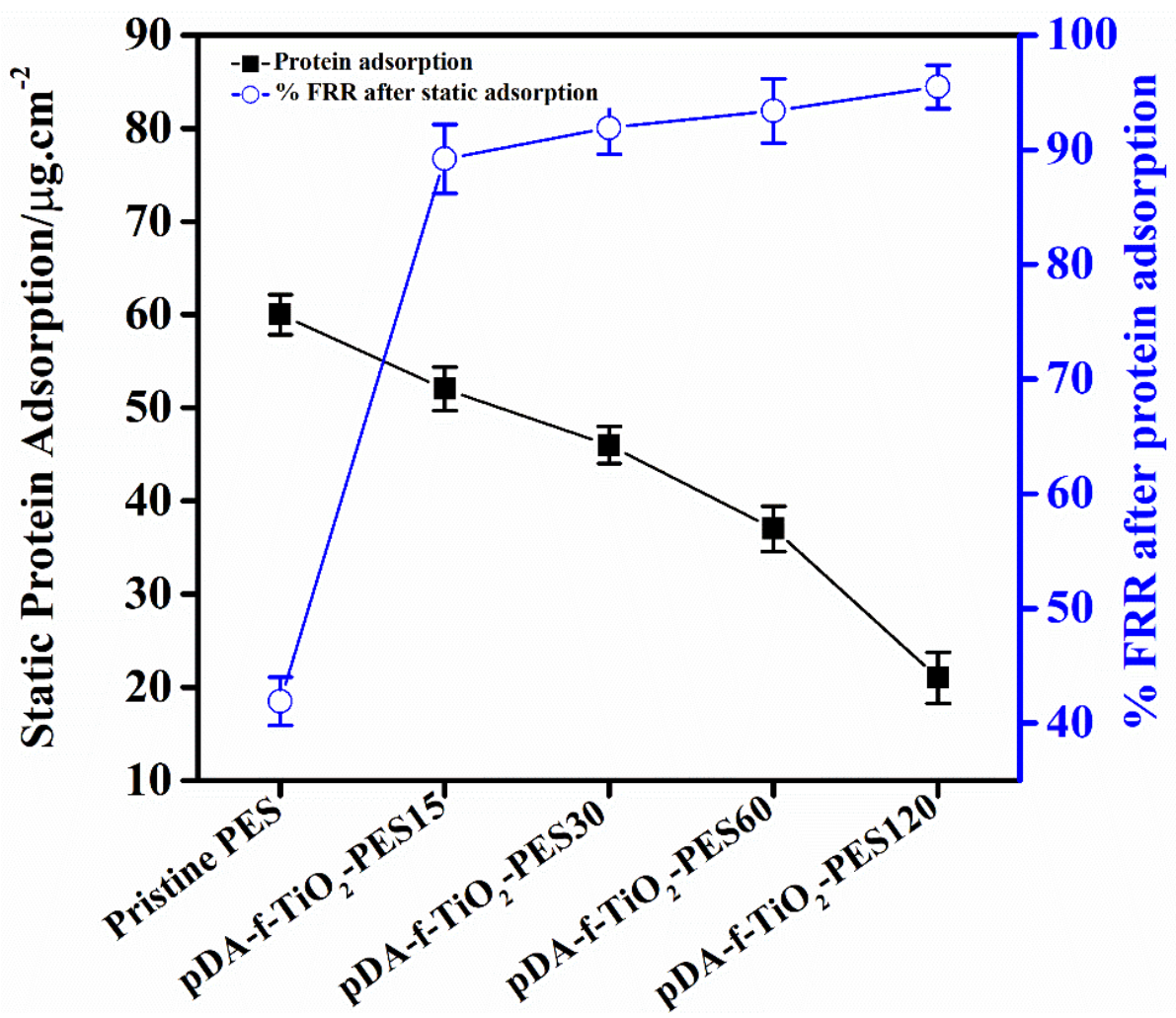

Fig. 8. Static protein adsorption and \% FRR after protein adsorption of pristine PES and modified PES membranes. $1 \mathrm{~g} / 1$ of BSA solution was used in this study as foulant model. 
3.5. Anti-fouling performance, and fouling resistance analysis of membranes

The membrane fouling was quantitatively studied, in terms of total fouling resistance $\left(\mathrm{R}_{\mathrm{t}}\right)$, which is caused primarily by the adsorption of protein on the membrane surface or inside the pores. The total fouling resistance is consisted of two fouling resistances that are reversible fouling resistance $\left(R_{r}\right)$ and irreversible fouling resistance $\left(R_{i r}\right)$. $R_{r}$ occurs due to the loose attachment of foulants on the membrane surface, while $\mathrm{R}_{\mathrm{ir}}$ arises due to the adsorption of foulants. As seen in Table 2, the discrepancies in the results of $R_{t}$ were not remarkable for all PES membranes, whereas the variations in the $R_{r}$ and $R_{i r}$ were pronounced. The hybrid PES membranes showed a significant increase in the $\mathrm{R}_{\mathrm{r}}$ ratio and gradual decrease in $\mathrm{R}_{\text {ir }}$ ratio when the time coating of pDA-f- $\mathrm{TiO}_{2}$ layer increased compared with the pristine PES membranes, which has shown highest $\mathrm{R}_{\mathrm{ir}}$ ratio, and lowest $\mathrm{R}_{\mathrm{r}}$ ratio. These results indicate that $\mathrm{pDA}-\mathrm{f}-\mathrm{TiO}_{2}$ layer has improved the anti-fouling properties of PES membranes. The presence of polydopamine and $\mathrm{TiO}_{2}$ can provide a good hydrophilic performance, thereby reducing the adhesion of organic foulants on the surface of membranes [57, 58].

Table 2. Fouling resistance for PES and modified PES UF membranes.

\begin{tabular}{|c|c|c|c|c|c|}
\hline $\begin{array}{l}\text { Membrane } \\
\text { Samples }\end{array}$ & $\% \mathbf{R}_{\mathrm{t}}$ & $\% \mathbf{R}_{r}$ & $\% \mathbf{R}_{\text {ir }}$ & $\%\left(\mathbf{R}_{\mathrm{r}} / \mathbf{R}_{\mathrm{t}}\right)$ & $\%\left(\mathbf{R}_{\mathrm{ir}} / \mathbf{R}_{\mathrm{t}}\right)$ \\
\hline Pristine PES & $95.61 \pm 2.31$ & $36.17 \pm 1.92$ & $59.44 \pm 1.88$ & 37.83 & 62.16 \\
\hline pDA-f-TiO2-PES15 & $98.94 \pm 1.99$ & $69.23 \pm 1.44$ & $29.71 \pm 1.65$ & 69.97 & 30.02 \\
\hline pDA-f-TiO 2 -PES30 & $99.39 \pm 1.31$ & $78.62 \pm 1.29$ & $20.77 \pm 1.73$ & 79.10 & 20.89 \\
\hline pDA-f-TiO 2 -PES60 & $98.95 \pm 1.54$ & $84.62 \pm 1.34$ & $14.33 \pm 1.55$ & 85.51 & 14.48 \\
\hline pDA-f-TiO $2-P E S 120$ & $98.64 \pm 1.66$ & $97.28 \pm 1.53$ & $1.36 \pm 1.89$ & 98.62 & 1.39 \\
\hline
\end{tabular}

\subsection{Anti-bacterial test of the modified membranes}

The antibacterial properties of pristine PES and hybrid PES membranes were performed in Table 3 and Fig.9. The bacterial attachment to the membranes surface appears via several mechanisms including electrostatic interaction and hydrophobic interaction [59]. It is concluded that bacterial attachment on a surface can occur via a layer of adsorbed protein; therefore, surfaces that resist protein adsorption should also resist the bacterial adhesion. Three membranes namely PES, pDA-f-TiO 2 -PES15 and pDA-f-TiO $2-\mathrm{PES} 120$ were selected for antibacterial test as a representative case and the data are presented in Table 3. As shown in Table 3. Compared with pristine PES membranes, the pDA-f-TiO $-\mathrm{PES} 120$ membranes exhibited good antibacterial ability and the total number of recovered viable E. coli from the pDA-f- 
$\mathrm{TiO}_{2}$-PES120 membranes is about $34 \%$ of that of PES membranes (100\%). And this is equal to $66 \%$ E. coli inactivation. The mechanism of this bactericidal effect is attributed to the existence of $\mathrm{TiO}_{2} \mathrm{NPs}$ and amphoteric nature of $\mathrm{pDA}$ on the surface of membrane, which have influence of killing E. coli bacteria. The bactericidal effect of $\mathrm{TiO}_{2}$ is due to the presence of reactive oxygen groups such as $\mathrm{H}_{2} \mathrm{O}_{2}, \mathrm{HO}$, and $\mathrm{O}_{2}{ }^{-}$generated by $\mathrm{TiO}_{2}$ nanoparticles. Numerous researchers have postulated that the mechanism for killing the E. coli bacteria by the bactericidal effect of $\mathrm{TiO}_{2}$ was lipid peroxidation reaction and $\mathrm{HO}$ attack $[60,61]$. Whilst the amphoteric character of $\mathrm{pDA}$ with positively charged primary and secondary amine groups could also have a direct impact on the bacteria. As bacterial membrane surfaces are negatively charged, the positively charged of amine groups of pDA could result in partial anti-bacterial activity [62]. After coupling $\mathrm{pDA}$ and $\mathrm{TiO}_{2}$ on the membrane surfaces, the membranes showed good anti-bacterial property, due to the synergistic effect of oxygen reactive groups of $\mathrm{TiO}_{2}$ and hydrophilic species of pDA (amine species), which results in damage of bacterial cell membrane [63].

Table 3. The total no of viable cells of pristine and modified PES membranes.

\begin{tabular}{|l|c|c|c|}
\hline Sample & PES & pDA-f-TiO $_{2}$-PES15 & pDA-f-TiO $_{2}$-PES120 \\
\hline Number of colonies & $289 \pm 0.32$ & $156 \pm 0.44$ & $99 \pm 0.77$ \\
\hline Normalized viable cells (E. coli) & $100 \%$ & $53 \%$ & $34 \%$ \\
\hline
\end{tabular}

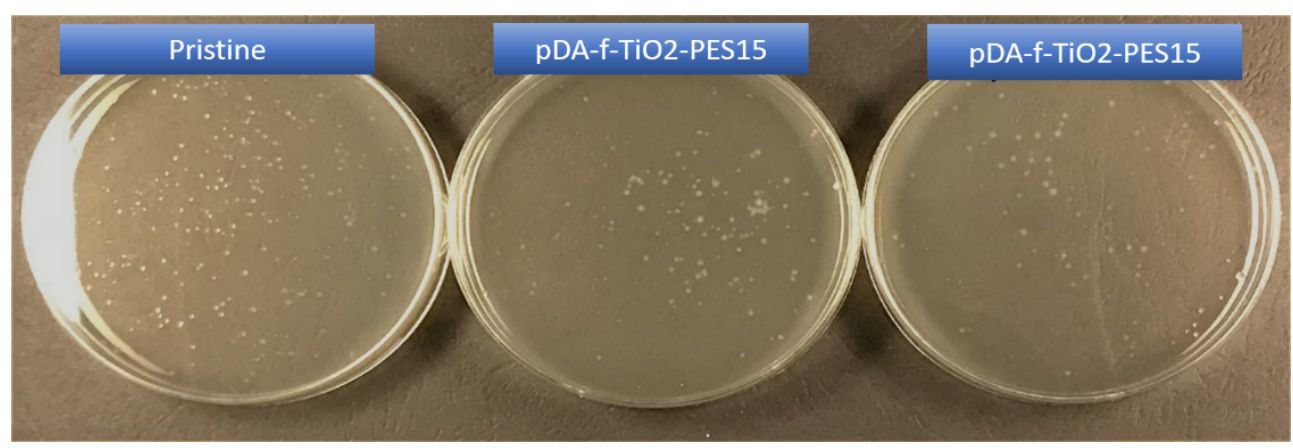

Fig. 9. Photographs (snip chat) showing the bacterial culture plates of E. coli of pristine and modified PES UF membranes. 


\subsection{Stability of the modified membranes}

To check the durability of the membrane under long-term operation, stability test was undertaken. The stability test was conducted in two parts: the first part is physical stability and the second one is chemical stability. The physical stability, on the first hand was conducted by immersing the pristine and modified PES membranes in a bottle of DDI water. The membrane samples together with the bottle were placed into a water bath under a continuous shaking at a speed of $100 \mathrm{rpm}$ at $30^{\circ} \mathrm{C}$ for 15 days.

The chemical stability, on the other hand was done by immersing the membranes in different membrane washing agent $\mathrm{NaOCl}$ solution (concentration $=500 \mathrm{ppm}, \mathrm{pH}=9.5$ ), sodium hydroxide solution at $\mathrm{pH}=13$ and hydrochloric acid solution at $\mathrm{pH}=2$ respectively. Each chemical stability test lasted for 15 days. The membranes after physical and chemical washing were characterised by CA and membrane performance and the results are tabulated (3.4-3.9).

Regarding the physical stability, the results of contact angle, pure water flux, \% BSA rejection, \% FRR and protein adsorption of pristine and modified PES membranes didn't change significantly in comparison with the membranes before washing the membranes in water. That's mean, the hydrophilic coated layer didn't peel off during the immersing the membranes in water for 15 days. This result indicates that the grafted $\mathrm{TiO}_{2} \mathrm{NPs}$ are tightly embedded on the PES membrane surfaces. See Tables (S1-S3) in Supplementary information (SI).

For chemical stability, the results of contact angle and water flux are shown in Tables (S4-S6) in SI, the modified PES membranes have kept excellent stability (no distinct changes in contact angle or in water flux) under acidic environment $(\mathrm{HCl})$ due to the fact that the polydopamine is stable in acidic, neutral and weak basis coating solutions[64, 65]. However, for sodium hydroxide $(\mathrm{NaOH})$, the water flux of the modified PES membranes was increased with the washing time. The changes in water flux indicates that the coated layers are not completely stable in a strong alkaline agent, whereas the polydopamine disintegrates in a strongly alkaline environment. The flux values of all the modified PES membranes after immersing in $\mathrm{NaOH}$ solution for 15 days are almost 1.5 times higher than the initial flux. Regarding the washing $\mathrm{NaOCl}$, the water flux of the modified PES membranes was also increased, almost 3 times higher than initial flux. The polydopamine reacts with $\mathrm{NaOCl}$ solution, producing a complex mixture of products[48]. Some interactions between pDA-f$\mathrm{TiO}_{2}$ layer with the original membrane maybe occurs in hypochlorite environment, which damages the membrane structure and leads to increase the water flux. The values of contact 
angle of the modified membranes after immersing in $\mathrm{NaOH}$ solution and $\mathrm{NaOCl}$ didn't change significantly, indicating the membranes still have hydrophilic property after chemical washing.

\section{Conclusions}

We provide a versatile and facile method to attach $\mathrm{TiO}_{2}$ NPs on the PES membranes in a one-pot reaction using in-situ dip coating of hydrophilic layer of pDA-f- $\mathrm{TiO}_{2}$. The modification layer of $\mathrm{pDA}-\mathrm{f}-\mathrm{TiO}_{2}$ significantly reduced the membrane pore size according to the SEM analysis and remarkably improved the membrane selectivity. The hydrophilicity and permeate flux have been improved after coating for different intervals (15, 30, 60 and $120 \mathrm{~min})$. The modification layer diminished the adhesion of organic macromolecules (BSA) on the surface of membrane. Moreover, the hybrid PES membrane showed higher antifouling performance and strong anti-bacterial properties compared to the pristine one. The stability test shows that the coated layer is stable after long time usage. This coating process is a facile technique to be implemented in the industry.

\section{AUTHOR INFORMATION}

\section{Corresponding Author}

* E-mail: bradley.ladewig@kit.edu

\section{Author Contributions}

The manuscript was written through contributions of all authors. All authors have given approval to the final version of the manuscript.

\section{Acknowledgments}

Muayad al-Shaeli acknowledges scholarship support from the Iraqi Government. Muayad alShaeli thanks Dr. Stefan J. D. Smith for helpful discussions and Dr. Chris Easton for his assistance with XPS measurements. 


\section{References}

[1] M. Shannon, P. Bohn, M. Elimelech, J. Georgiadis, B. Maries, A. Mayes, Science and technology for water purification in the coming decades Nature, 452 (2008) 301-310.

[2] G. Kwon, A.K. Kota, Y. Li, A. Sohani, J.M. Mabry, A. Tuteja, On-demand separation of oil-water mixtures, Advanced Materials, 24 (2012) 3666-3671.

[3] Q. Li, Q.Y. Bi, H.H. Lin, L.X. Bian, X.L. Wang, A novel ultrafiltration (UF) membrane with controllable selectivity for protein separation, Journal of Membrane Science, 427 (2013) $155-167$.

[4] J.M. Arnal, B. Garcia-Fayos, J. Lora, G. Verdú, M. Sancho, AQUAPOT: study of several cleaning solutions to recover permeate flow in a humanitarian drinking water treatment facility based on spiral wound UF membrane. Preliminary test (I), Desalination, 221 (2008) 331-337. [5] J.M. Arnal, B. Garcia-Fayos, G. Verdu, J. Lora, M. Sancho, AQUAPOT: Study of the causes in reduction of permeate flow in spiral wound UF membrane. Simulation of a nonrigorous cleaning protocol in a drinkable water treatment facility, Desalination, 222 (2008) 513-518.

[6] J.M. Arnal, B. García-Fayos, M. Sancho, G. Verdú, J. Lora, Design and installation of a decentralized drinking water system based on ultrafiltration in Mozambique, Desalination, 250 (2010) 613-617.

[7] M.M. Pendergast, E.M.V. Hoek, A review of water treatment membrane nanotechnologies, Energy and Environmental Science, 4 (2011) 1946-1971.

[8] A. Asatekin, S. Kang, M. Elimelech, A.M. Mayes, Anti-fouling ultrafiltration membranes containing polyacrylonitrile-graft-poly(ethylene oxide) comb copolymer additives, Journal of Membrane Science, 298 (2007) 136-146.

[9] K.J. Howe, M.M. Clark, Fouling of microfiltration and ultrafiltration membranes by natural waters, Environmental Science and Technology, 36 (2002) 3571-3576.

[10] M. Radjabian, V. Abetz, Tailored pore sizes in integral asymmetric membranes formed by blends of block copolymers, Advanced Materials, 27 (2015) 352-355.

[11] J. Marchese, M. Ponce, N.A. Ochoa, P. Prádanos, L. Palacio, A. Hernández, Fouling behaviour of polyethersulfone UF membranes made with different PVP, Journal of Membrane Science, 211 (2003) 1-11.

[12] J.J. Qin, M.H. Oo, Y. Li, Development of high flux polyethersulfone hollow fiber ultrafiltration membranes from a low critical solution temperature dope via hypochlorite treatment, Journal of Membrane Science, 247 (2005) 137-142. 
[13] F. Shi, Y. Ma, J. Ma, P. Wang, W. Sun, Preparation and chacterization of PVDF/TiO2 hybrid membranes with ionic liquid modified nano-TiO2 particles, Journal of Membrane Science, 427 (2013) 259-269.

[14] W. Zhao, J. Huang, B. Fang, S. Nie, N. Yi, B. Su, H. Li, C. Zhao, Modification of polyethersulfone membrane by blending semi-interpenetrating network polymeric nanoparticles, Journal of Membrane Science, 369 (2011) 258-266.

[15] L. Liu, D.Y.W. Di, H. Park, M. Son, H.G. Hur, H. Choi, Improved antifouling performance of polyethersulfone (PES) membrane via surface modification by CNTs bound polyelectrolyte multilayers, RSC Advances, 5 (2015) 7340-7348.

[16] C. Zhao, J. Xue, F. Ran, S. Sun, Modification of polyethersulfone membranes - A review of methods, Progress in Materials Science, 58 (2013) 76-150.

[17] Y.Q. Wang, T. Wang, Y.L. Su, F.B. Peng, H. Wu, Z.Y. Jiang, Protein-adsorptionresistance and permeation property of polyethersulfone and soybean phosphatidylcholine blend ultrafiltration membranes, Journal of Membrane Science, 270 (2006) 108-114.

[18] L. Yan, Y.S. Li, C.B. Xiang, S. Xianda, Effect of nano-sized A12O3-particle addition on PVDF ultrafiltration membrane performance, Journal of Membrane Science, 276 (2006) 162167.

[19] S. Liang, K. Xiao, Y. Mo, X. Huang, A novel ZnO nanoparticle blended polyvinylidene fluoride membrane for anti-irreversible fouling, Journal of Membrane Science, 394-395 (2012) 184-192.

[20] C.S. Ong, P.S. Goh, W.J. Lau, N. Misdan, A.F. Ismail, Nanomaterials for biofouling and scaling mitigation of thin film composite membrane: A review, Desalination, 393 (2016) 2-15. [21] X. Fang, J. Li, X. Li, S. Pan, X. Sun, J. Shen, W. Han, L. Wang, B. Van der Bruggen, Iron-tannin-framework complex modified PES ultrafiltration membranes with enhanced filtration performance and fouling resistance, Journal of Colloid and Interface Science, 505 (2017) 642-652.

[22] E. Bet-Moushoul, Y. Mansourpanah, K. Farhadi, M. Tabatabaei, TiO $<\inf >2</$ inf $>$ nanocomposite based polymeric membranes: A review on performance improvement for various applications in chemical engineering processes, Chemical Engineering Journal, 283 (2016) 29-46.

[23] A. Nguyen, S. Azari, L. Zou, Coating zwitterionic amino acid l-DOPA to increase fouling resistance of forward osmosis membrane, Desalination, 312 (2013) 82-87.

[24] H. Lee, S.M. Dellatore, W.M. Miller, P.B. Messersmith, Mussel-inspired surface chemistry for multifunctional coatings, Science, 318 (2007) 426-430. 
[25] B.P. Tripathi, N.C. Dubey, F. Simon, M. Stamm, Thermo responsive ultrafiltration membranes of grafted poly(N-isopropyl acrylamide) via polydopamine, RSC Advances, 4 (2014) 34073-34083.

[26] J.I. Clodt, V. Filiz, S. Rangou, K. Buhr, C. Abetz, D. Höche, J. Hahn, A. Jung, V. Abetz, Double stimuli-responsive isoporous membranes via post-modification of ph-sensitive selfassembled diblock copolymer membranes, Advanced Functional Materials, 23 (2013) 731-738. [27] B.P. Tripathi, P. Das, F. Simon, M. Stamm, Ultralow fouling membranes by surface modification with functional polydopamine, European Polymer Journal, 99 (2018) 80-89.

[28] Q. Liu, A. Singh, L. Liu, Amino acid-based zwitterionic poly(serine methacrylate) as an antifouling material, Biomacromolecules, 14 (2013) 226-231.

[29] P.H.H. Duong, T.S. Chung, S. Wei, L. Irish, Highly permeable double-skinned forward osmosis membranes for anti-fouling in the emulsified oil-water separation process, Environmental Science and Technology, 48 (2014) 4537-4545.

[30] K. Zhu, G. Wang, S. Zhang, Y. Du, Y. Lu, R. Na, Y. Mu, Y. Zhang, Preparation of organicinorganic hybrid membranes with superior antifouling property by incorporating polymermodified multiwall carbon nanotubes, RSC Advances, 7 (2017) 30564-30572.

[31] T. Cai, X. Li, C. Wan, T.S. Chung, Zwitterionic polymers grafted poly(ether sulfone) hollow fiber membranes and their antifouling behaviors for osmotic power generation, Journal of Membrane Science, 497 (2016) 142-152.

[32] G. Han, J.S. de Wit, T.S. Chung, Water reclamation from emulsified oily wastewater via effective forward osmosis hollow fiber membranes under the PRO mode, Water Research, 81 (2015) 54-63.

[33] G. Han, S. Zhang, X. Li, N. Widjojo, T.S. Chung, Thin film composite forward osmosis membranes based on polydopamine modified polysulfone substrates with enhancements in both water flux and salt rejection, Chemical Engineering Science, 80 (2012) 219-231.

[34] X. Li, T. Cai, G.L. Amy, T.S. Chung, Cleaning strategies and membrane flux recovery on anti-fouling membranes for pressure retarded osmosis, Journal of Membrane Science, 522 (2017) 116-123.

[35] S. Kasemset, A. Lee, D.J. Miller, B.D. Freeman, M.M. Sharma, Effect of polydopamine deposition conditions on fouling resistance, physical properties, and permeation properties of reverse osmosis membranes in oil/water separation, Journal of Membrane Science, 425-426 (2013) 208-216.

[36] J. Jiang, L. Zhu, L. Zhu, B. Zhu, Y. Xu, Surface characteristics of a self-polymerized dopamine coating deposited on hydrophobic polymer films, Langmuir, 27 (2011) 14180-14187. 
[37] J. Ou, J. Wang, D. Zhang, P. Zhang, S. Liu, P. Yan, B. Liu, S. Yang, Fabrication and biocompatibility investigation of $\mathrm{TiO}<\mathrm{inf}>2</ \mathrm{inf}>$ films on the polymer substrates obtained via a novel and versatile route, Colloids and Surfaces B: Biointerfaces, 76 (2010) 123-127.

[38] B.P. Tripathi, N.C. Dubey, M. Stamm, Polyethylene glycol cross-linked sulfonated polyethersulfone based filtration membranes with improved antifouling tendency, Journal of Membrane Science, 453 (2014) 263-274.

[39] M. Mänttäri, M. Nyström, Critical flux in NF of high molar mass polysaccharides and effluents from the paper industry, Journal of Membrane Science, 170 (2000) 257-273.

[40] M. Mänttäri, L. Puro, J. Nuortila-Jokinen, M. Nyström, Fouling effects of polysaccharides and humic acid in nanofiltration, Journal of Membrane Science, 165 (2000) 1-17.

[41] M. Kulovaara, S. Metsämuuronen, M. Nyström, Effects of aquatic humic substances on a hydrophobic ultrafiltration membrane, Chemosphere, 38 (1999) 3485-3496.

[42] J. Zhang, Z. Xu, W. Mai, C. Min, B. Zhou, M. Shan, Y. Li, C. Yang, Z. Wang, X. Qian, Improved hydrophilicity, permeability, antifouling and mechanical performance of PVDF composite ultrafiltration membranes tailored by oxidized low-dimensional carbon nanomaterials, Journal of Materials Chemistry A, 1 (2013) 3101-3111.

[43] R. Zhou, P.F. Ren, H.C. Yang, Z.K. Xu, Fabrication of antifouling membrane surface by poly(sulfobetaine methacrylate)/polydopamine co-deposition, Journal of Membrane Science, 466 (2014) 18-25.

[44] F. Perreault, M.E. Tousley, M. Elimelech, Thin-Film Composite Polyamide Membranes Functionalized with Biocidal Graphene Oxide Nanosheets, Environmental Science and Technology Letters, 1 (2013) 71-76.

[45] H. Shi, Y. He, Y. Pan, H. Di, G. Zeng, L. Zhang, C. Zhang, A modified mussel-inspired method to fabricate $\mathrm{TiO}<\mathrm{inf}>2</ \mathrm{inf}>$ decorated superhydrophilic PVDF membrane for oil/water separation, Journal of Membrane Science, 506 (2016) 60-70.

[46] H. Susanto, M. Ulbricht, Characteristics, performance and stability of polyethersulfone ultrafiltration membranes prepared by phase separation method using different macromolecular additives, Journal of Membrane Science, 327 (2009) 125-135.

[47] F. Gao, G. Zhang, Q. Zhang, X. Zhan, F. Chen, Improved Antifouling Properties of Poly(Ether Sulfone) Membrane by Incorporating the Amphiphilic Comb Copolymer with Mixed Poly(Ethylene Glycol) and Poly(Dimethylsiloxane) Brushes, Industrial and Engineering Chemistry Research, 54 (2015) 8789-8800. 
[48] Z.Y. Xi, Y.Y. Xu, L.P. Zhu, Y. Wang, B.K. Zhu, A facile method of surface modification for hydrophobic polymer membranes based on the adhesive behavior of poly(DOPA) and poly(dopamine), Journal of Membrane Science, 327 (2009) 244-253.

[49] R.X. Zhang, L. Braeken, P. Luis, X.L. Wang, B. Van der Bruggen, Novel binding procedure of $\mathrm{TiO}<\mathrm{inf}>2</ \mathrm{inf}>$ nanoparticles to thin film composite membranes via selfpolymerized polydopamine, Journal of Membrane Science, 437 (2013) 179-188.

[50] L. Shao, Z.X. Wang, Y.L. Zhang, Z.X. Jiang, Y.Y. Liu, A facile strategy to enhance PVDF ultrafiltration membrane performance via self-polymerized polydopamine followed by hydrolysis of ammonium fluotitanate, Journal of Membrane Science, 461 (2014) 10-21.

[51] S. Azari, L. Zou, Using zwitterionic amino acid l-DOPA to modify the surface of thin film composite polyamide reverse osmosis membranes to increase their fouling resistance, Journal of Membrane Science, 401-402 (2012) 68-75.

[52] Q. Wang, X. Wang, Z. Wang, J. Huang, Y. Wang, PVDF membranes with simultaneously enhanced permeability and selectivity by breaking the tradeoff effect via atomic layer deposition of TiO2, Journal of Membrane Science, 442 (2013) 57-64.

[53] B.P. Tripathi, N.C. Dubey, S. Choudhury, M. Stamm, Antifouling and tunable amino functionalized porous membranes for filtration applications, Journal of Materials Chemistry, 22 (2012) 19981-19992.

[54] J. Cui, Y. Ju, K. Liang, H. Ejima, S. Lörcher, K.T. Gause, J.J. Richardson, F. Caruso, Nanoscale engineering of low-fouling surfaces through polydopamine immobilisation of zwitterionic peptides, Soft Matter, 10 (2014) 2656-2663.

[55] J.C. Hower, M.T. Bernards, S. Chen, H.K. Tsao, Y.J. Sheng, S. Jiang, Hydration of "Nonfouling" functional groups, Journal of Physical Chemistry B, 113 (2009) 197-201.

[56] S. Herrwerth, W. Eck, S. Reinhardt, M. Grunze, Factors that determine the protein resistance of oligoether self-assembled monolayers - Internal hydrophilicity, terminal hydrophilicity, and lateral packing density, Journal of the American Chemical Society, 125 (2003) 9359-9366.

[57] S.S. Madaeni, N. Ghaemi, Characterization of self-cleaning RO membranes coated with $\mathrm{TiO} 2$ particles under UV irradiation, Journal of Membrane Science, 303 (2007) 221-233.

[58] S.S. Madaeni, S. Zinadini, V. Vatanpour, A new approach to improve antifouling property of PVDF membrane using in situ polymerization of PAA functionalized $\mathrm{TiO} 2$ nanoparticles, Journal of Membrane Science, 380 (2011) 155-162. 
[59] I. Banerjee, R.C. Pangule, R.S. Kane, Antifouling coatings: Recent developments in the design of surfaces that prevent fouling by proteins, bacteria, and marine organisms, Advanced Materials, 23 (2011) 690-718.

[60] S.H. Kim, S.Y. Kwak, B.H. Sohn, T.H. Park, Design of TiO2 nanoparticle self-assembled aromatic polyamide thin-film-composite (TFC) membrane as an approach to solve biofouling problem, Journal of Membrane Science, 211 (2003) 157-165.

[61] S.Y. Kwak, S.H. Kim, S.S. Kim, Hybrid organic/inorganic reverse osmosis (RO) membrane for bactericidal anti-fouling. 1. Preparation and characterization of $\mathrm{TiO} 2$ nanoparticle self-assembled aromatic polyamide thin-film-composite (TFC) membrane, Environmental Science and Technology, 35 (2001) 2388-2394.

[62] V. Kochkodan, S. Tsarenko, N. Potapchenko, V. Kosinova, V. Goncharuk, Adhesion of microorganisms to polymer membranes: a photobactericidal effect of surface treatment with TiO2, Desalination, 220 (2008) 380-385.

[63] H.M. Hegab, A. ElMekawy, T.G. Barclay, A. Michelmore, L. Zou, C.P. Saint, M. GinicMarkovic, Effective in-situ chemical surface modification of forward osmosis membranes with polydopamine-induced graphene oxide for biofouling mitigation, Desalination, 385 (2016) 126-137.

[64] J. Jiang, L. Zhu, L. Zhu, H. Zhang, B. Zhu, Y. Xu, Antifouling and antimicrobial polymer membranes based on bioinspired polydopamine and strong hydrogen-bonded poly(n -vinyl pyrrolidone), ACS Applied Materials and Interfaces, 5 (2013) 12895-12904.

[65] H. Wei, J. Ren, B. Han, L. Xu, L. Han, L. Jia, Stability of polydopamine and poly(DOPA) melanin-like films on the surface of polymer membranes under strongly acidic and alkaline conditions, Colloids and surfaces. B, Biointerfaces, 110 (2013) 22-28. 